\title{
ERCP failure: EUS gallbladder drainage as first alternative?
}

\section{(ㄷ) (1) $(2) \div$}

\author{
Author \\ Anthony Yuen Bun Teoh \\ Institution \\ Department of Surgery, Prince of Wales Hospital, The \\ Chinese University of Hong Kong, Shatin, Hong Kong, China \\ Bibliography \\ DOI https://doi.org/10.1055/a-0830-4675 | \\ Endoscopy International Open 2019; 07: E662-E663
}

\section{(c) Georg Thieme Verlag KG Stuttgart · New York eISSN 2196-9736}

Corresponding author

Prof. Anthony Y.B. Teoh, Department of Surgery, Prince of

Wales Hospital, Shatin, New Territories, Hong Kong SAR

Fax: +85235057974

anthonyteoh@surgery.cuhk.edu.hk
Endoscopic ultrasound-guided gallbladder drainage (EUS-GBD) is gaining popularity as an option for drainage of the gallbladder in patients suffering from acute cholecystitis who are at high risk for cholecystectomy [1]. The procedure could also be used to convert permanent cholecystostomy to internal drainage [2]. EUS-GBD has been shown by multiple retrospective studies to be associated with reduced adverse events (AEs), reinterventions and readmissions [3-5]. The advent of a cauterytipped lumen-apposing stent also significantly reduced the complexity of the procedure and allowed for creation of a secure anastomosis [6 - 7]. In this issue of Endoscopy International Open, Chang et al presented a series of nine patients who received EUS-GBD as a method of drainage in malignant biliary obstruction with failed ERCP [8]. They reported a clinical success rate of $77.78 \%$. One patient suffered from recurrent obstruction at 7 months after EUS-GBD and received EUS-guided choledochoduodenostomy.

Performance of EUS-GBD in the setting of malignant biliary obstruction (MBO) is similar to the principle of surgical cholecystojejunostomy. In the 1980 s and 1990 s, there was extensive debate in the surgical literature about whether cholecystojejunostomy or hepaticojejunostomy provided better palliation of MBO. There are several concerns about using the gallbladder as a conduit for biliary drainage. First, effectiveness of the biliary drainage depends on the patency of the cystic duct. In a retrospective study assessing incidence of patent cystic ducts on cholangiograms performed by endoscopic retrograde cholangiopancreatography (ERCP) in patients with $\mathrm{MBO}$, only $50 \%$ of patients had a patent hepatocystic junction [9]. Furthermore, two-thirds of the remaining patients had obstructions less than $1 \mathrm{~cm}$ from the hepatocystic junction, potentially increasing risk of future cystic duct obstruction. Results from multiple surgical series demonstrated that the overall rate of recurrent biliary obstruction was between $8 \%$ and $48 \%$ [10-12]. Thus, proximity of the cystic duct opening to the site of obstruction may be a risk factor for recurrent obstruction.

EUS-guided biliary drainage (EUS-BD) can be achieved by a number of approaches, either transpapillary or transmurally [13-14]. For transpapillary approaches, EUS-rendezvous ERCP or antegrade stenting could be performed. For transmural procedures, EUS-guided choledochoduodenostomy (CDS) and hepaticogastrostomy (HGS) could be performed. Performance of these procedures during the learning curve can be associated with a risk of AEs. Performance of them by an endoscopist fluent in them is associated with procedural $A E$ rates comparable to that of ERCP. The availability of single-step devices for CDS and hepaticogastrostomy will further improve the ease and safety of performing these procedures [15-16]. The benefit of transmural drainage is that the stent is placed in the bile duct far from the tumor, thus risk of tumor in-growth is significantly reduced. Indeed, a recent randomized study demonstrated that EUS-BD may provide higher stent patency rates and lower AE rates (particularly for pancreatitis) as compared to ERCP in unresectable $\mathrm{MBO}$ [16].

Hence, in the presence of available expertise and devices, EUS-BD should still be the first choice for draining MBO. In the event that EUS-BD cannot be performed, EUS-GBD can then potentially provide another option for biliary drainage.

\section{Competing interests}

Prof. Anthony Y.B. Teoh is a consultant for Boston Scientific, Cook, Taewoong, and Microtech Medical Corporations. 


\section{References}

[1] Mori Y, Itoi T, Baron TH et al. Tokyo Guidelines 2018: management strategies for gallbladder drainage in patients with acute cholecystitis (with videos). J Hepatobiliary Pancreat Sci 2018; 25: 87 - 95

[2] Law R, Grimm IS, Stavas JM et al. Conversion of percutaneous cholecystostomy to internal transmural gallbladder drainage using an endoscopic ultrasound-guided, lumen-apposing metal stent. Clin Gastroenterol Hepatol 2016; 14: 476 - 480

[3] Teoh AY, Serna C, Penas I et al. Endoscopic ultrasound-guided gallbladder drainage reduces adverse events compared with percutaneous cholecystostomy in patients who are unfit for cholecystectomy. Endoscopy 2017; 49: 130 - 138

[4] Tyberg A, Saumoy M, Sequeiros EV et al. EUS-guided versus percutaneous gallbladder drainage: isn't it time to convert? J Clin Gastroenterol 2016; 52: $79-84$

[5] Irani S, Ngamruengphong S, Teoh A et al. Similar efficacies of endoscopic ultrasound gallbladder drainage with a lumen-apposing metal stent versus percutaneous transhepatic gallbladder drainage for acute cholecystitis. Clin Gastroenterol Hepatol 2017; 15: 738 - 745

[6] Teoh AY, Binmoeller KF, Lau JY. Single-step EUS-guided puncture and delivery of a lumen-apposing stent for gallbladder drainage using a novel cautery-tipped stent delivery system. Gastrointest Endosc 2014; 80: 1171

[7] Teoh AY, Chiu PW, Hon SF et al. Ex vivo comparative study using the Endolifter(R) as a traction device for enhancing submucosal visualization during endoscopic submucosal dissection. Surg Endosc 2013; 27: $1422-1427$
[8] Chang Al, Dong E, Kwok KK. Endoscopic ultrasound-guided transmural gallbladder drainage in malignant obstruction using a novel lumen-apposing stent - a case series (with video). Endosc Int Open 2018; 07: E655-E661

[9] Tarnasky PR, England RE, Lail LM et al. Cystic duct patency in malignant obstructive jaundice. An ERCP-based study relevant to the role of laparoscopic cholecystojejunostomy. Ann Surg 1995; 221: 265 - 271

[10] Eastman MC, Kune GA. The objectives of palliative surgery in pancreas cancer: a retrospective study of 73 cases. Aust N Z J Surg 1980; 50: $462-464$

[11] Watanapa P, Williamson RC. Surgical palliation for pancreatic cancer: developments during the past two decades. Br J Surg 1992; 79: 8-20

[12] Gough IR, Mumme G. Biliary and duodenal bypass for carcinoma of the head of the pancreas. J Surg Oncol 1984; 26: $282-284$

[13] Teoh AYB, Dhir V, Kida M et al. Consensus guidelines on the optimal management in interventional EUS procedures: results from the Asian EUS group RAND/UCLA expert panel. Gut 2018; 67: 1209-1228

[14] Dhir V, Isayama H, Itoi T et al. EUS-guided biliary and pancreatic duct interventions. Dig Endosc 2017; 29: 472 - 485

[15] Tsuchiya T, Teoh AYB, Itoi T et al. Long-term outcomes of EUS-guided choledochoduodenostomy using a lumen-apposing metal stent for malignant distal biliary obstruction: a prospective multicenter study. Gastrointest Endosc 2018; 87: 1138 - 1146

[16] Paik WH, Lee TH, Park DH et al. EUS-guided biliary drainage versus ercp for the primary palliation of malignant biliary obstruction: a multicenter randomized clinical trial. Am J Gastroenterol 2018; 113: $987-997$ 